\title{
Age and sex interaction in reported help seeking in response to chest pain
}

\author{
Joy Adamson, Jenny Donovan, Yoav Ben-Shlomo, Nish Chaturvedi and Ann Bowling
}

\begin{abstract}
Background

There is a growing literature suggesting that access to cardiology services is affected by age. However, there is a dearth of studies that have considered age and sex in conjunction.
\end{abstract}

Aim

This study aims to examine the impact of age, and its interaction with sex, on reported healthcare seeking, based on responses to symptom vignettes, in an attempt to standardise symptomatology across all responders.

\section{Design of study}

A cross-sectional survey design was utilised.

\section{Setting}

Primary care.

\section{Method}

A random sample of 911 individuals, stratified by sex, was selected from one practice in the UK. Participants were invited to state how they would react in response to the chest pain symptoms presented. Patterns of response were examined, by age and sex, using $\chi^{2}$ and logistic regression models.

\section{Results}

This study identified differences by age and sex in a general practice population in the propensity to seek health care. In particular, men aged 60-69 years and women aged 70 years and over were more likely to report healthcare seeking than younger responders.

For example, women aged 70 years and over had over three times greater odds of reporting contact with the GP compared to the reference category. Evidence for an interaction effect between age and sex was observed.

\section{Conclusion}

The results suggest that the inequity that has been demonstrated in access to cardiology services by age is not likely to be due to the patient's illness behaviour as, overall, older people are more likely than younger people to be willing to consult their doctors.

\section{Keywords}

aged; gender identity; heart; patient acceptance of health care.

\section{INTRODUCTION}

There are clear indications that older people have poorer access to appropriate care than their younger counterparts..$^{1-3}$ Despite policies orientated specifically for the health and health care of older people emphasising equity, ${ }^{4}$ age-related patterns of utilisation remain. ${ }^{5}$ Coronary heart disease (CHD) is an important condition to consider; its risk increases with age, it remains the major cause of death in many countries, by 2020 it is predicted to be the leading cause of disease burden worldwide, ${ }^{6}$ and, importantly, it has clear recommendations set out for appropriate treatment regimes. ${ }^{7}$ Therefore, much of the literature has centred around utilisation of services for CHD, where there is evidence for inequitable care by age (as well as other sociodemographic characteristics, including, sex, socioeconomic position, and ethnicity) ${ }^{8,9}$ at primary, secondary, and tertiary care levels. ${ }^{10,11}$ This is despite invasive treatments being shown to be effective among older age groups. ${ }^{12}$ More recent studies would also seem to suggest that there is an interaction between age and sex, for example, older women experiencing the 'double jeopardy' of inequity. ${ }^{8}$ However, there is a dearth of studies that

J Adamson, PhD, lecturer in epidemiology, Health Sciences, University of York, Heslington, York. J Donovan, PhD, professor; Y Ben-Shlomo, PhD, FFPHM, professor, University of Bristol, Social Medicine, Bristol. N Chaturvedi, MBBS, $P h D$, professor, Imperial College at St Mary's, National Heart and Lung Institute, London. A Bowling, PhD, professor, Department of Primary Care and Population Sciences, University College London, London.

Address for correspondence

Dr Joy Adamson, University of York, Health Sciences, 1st Floor, Seebohm Rowntree Building, Heslington, York, YO10 5DD. E-mail: ja14@york.ac.uk

Submitted: 4 September 2007; Editor's response: 19 November 2007; final acceptance: 4 January 2008.

(c)British Journal of General Practice.

This article was originally online first. Cite this article as: Br J Gen Pract 2008; 58: 318-323. Advance online publication. DOI: $10.3399 /$ bjgp08X279670 
have considered age and sex in conjunction, ${ }^{8}$ or that have explored the mechanisms underlying these age and sex differences.

Attempting to tease out the possible mechanisms behind these observed inequalities is a difficult task. There are many levels at which differential activities may occur: in the individual interpretation of symptoms and uptake of health services, primary care diagnosis and management, and management at specialist level. ${ }^{13}$ This study aims to consider the patient, at the start of this potential chain of events, through examining how individuals report they would react in response to a standardised set of symptoms. In 1964, Williamson et al published their landmark paper, which suggested that multiple health problems and disabilities present in a community sample of older people were not known to their GP. ${ }^{14}$ Other studies have noted that older people may have a reluctance to seek treatment, ${ }^{15}$ for example, due to the 'normalisation' of their symptoms in terms of age, even if these symptoms remain highly disruptive; ${ }^{-16}$ this has also been termed 'age attribution'. ${ }^{17}$ This body of work has contributed to the prevailing view of the stoical older person, who may be less likely than other age groups to seek medical intervention. Separately, it has been suggested that women do not identify their symptoms as relating to $\mathrm{CHD}$, as $\mathrm{CHD}$ is viewed as largely a male disease. ${ }^{18}$

Most studies considering differential service utilisation by different social groups have analysed patient databases; however, such designs make it difficult to adjust for differences in symptomatology and, hence, different patterns of need. This study has investigated the impact of age (and its interaction with sex) on reported healthcare seeking, based on responses to symptom vignettes, in an attempt to standardise symptomatology across all responders.

\section{METHOD}

A sample of 1700 individuals from one general practice in the south west of England, stratified by sex, was randomly selected from the practice list. The practice was selected as it contained a group of individuals from a wide range of socioeconomic backgrounds. The selection was made using census profiles of several practices, including the enumeration district value for three census indicators (Townsend, Jarmen, and Carstairs). The scores were calculated based on enumeration district values that define the geographical areas of the practice population. Using this information, it was possible to identify a practice with two branches - one that was situated in a relatively deprived area and the other in a relatively affluent location.

\section{How this fits in}

There is evidence for age inequality in access to cardiology services. A stereotype exists of the older stoical patient who has a reluctance to seek medical help. This study indicated a reported increasing willingness with increasing age to contact healthcare services. Inequity in access to cardiology services by age is not likely to be due to the patient's illness behaviour.

The patient list was reviewed by the GPs to exclude any person with terminal or serious psychiatric illness. From this sample, 1500 individuals were randomly selected to participate in the survey; however, correct address details were only available for a subset of 1287 individuals (based largely on information from post office returns). After two attempts to contact responders, following the initial mail shot, a total of 911 completed questionnaires was received (response rate $71 \%)$. Responders were slightly older than nonresponders, and were more likely to be female.

The questionnaire contained a short vignette, describing a scenario that could be related to CHD, in which the protagonist ('Chris') experienced an episode of chest pain on exertion (Box 1). The scenario was designed to be sex neutral, so that the clinical symptoms could reflect a range of possible diagnoses and actions that could be taken in response. Further details of the vignette are available elsewhere. ${ }^{13}$

Responders were asked to record how they would react if they themselves were experiencing the symptoms described in the vignette. They were able to specify whether they would call or attend the GP, and how likely they were to do so (selecting from definitely, probably, unlikely, or not at all). For the outcome, responders were dichotomised into stating they would definitely/probably access the GP, compared to unlikely or not at all.

Data were collected on date of birth, and a responder's age at the time of completing the questionnaire was calculated. A categorical variable was created that divided responders into 10-year age bands (under 40 years, 40-49 years, 50-59 years, 60-69 years, and 70 years and over).

\section{Box 1. Vignette.}

Chris is 55 years old and has generally good health, but is overweight and doesn't do much exercise. Chris's grandchildren have come to stay for the weekend. Later that evening one of the grandchildren has a headache. Chris starts carrying the child up the stairs to the bedroom. Suddenly, Chris feels a pain in the chest. The pain is so bad that Chris feels a bit sick and has to put the child down. After about 5 minutes, the pain wears off and Chris feels fine. Chris has had the pain once before, following a large meal. 


\begin{tabular}{|c|c|c|c|c|}
\hline & \multicolumn{2}{|c|}{ Males $(n=367)$} & \multicolumn{2}{|c|}{ Females $(n=427)$} \\
\hline & $n$ & $\%(95 \% \mathrm{Cl})$ & $n$ & $\%(95 \% \mathrm{Cl})$ \\
\hline \multicolumn{5}{|l|}{ Age, years } \\
\hline$<40$ & 80 & 21.8 (17.7 to 26.4 ) & 89 & 20.8 (17.1 to 25.0$)$ \\
\hline $40-49$ & 87 & 23.7 (19.4 to 28.4 ) & 71 & 16.6 (13.2 to 20.5$)$ \\
\hline $50-59$ & 83 & 22.6 (18.4 to 27.2$)$ & 120 & 28.1 (23.9 to 32.6$)$ \\
\hline $60-69$ & 80 & 21.8 (17.7 to 26.4 ) & 95 & 22.3 (18.4 to 26.5$)$ \\
\hline$\geq 70$ & 37 & 10.1 (7.2 to 13.6$)$ & 52 & $12.2(9.2$ to 15.7$)$ \\
\hline Mean (SD) & 52.2 & (12.9) & 53.6 & (13.0) \\
\hline \multicolumn{5}{|l|}{ Socioeconomic index } \\
\hline 0 & 73 & 19.9 (15.9 to 24.3$)$ & 76 & 17.8 (14.3 to 21.8$)$ \\
\hline 1 & 78 & 21.3 (17.2 to 25.8$)$ & 85 & 19.9 (16.2 to 24.0$)$ \\
\hline 2 & 138 & 37.6 (32.6 to 42.8 ) & 170 & 39.8 (35.1 to 44.6$)$ \\
\hline 3 & 78 & 21.3 (17.2 to 25.8 ) & 96 & 22.5 (18.6 to 26.7$)$ \\
\hline \multicolumn{5}{|l|}{ Contact GP } \\
\hline Definitely/probably & 196 & 53.4 (48.2 to 58.6 ) & 269 & 63.0 (58.2 to 67.6$)$ \\
\hline \multicolumn{5}{|l|}{ Anxiety } \\
\hline Very worried & 83 & 22.6 (18.4 to 27.2 ) & 93 & 21.8 (18.0 to 26.0 ) \\
\hline \multicolumn{5}{|l|}{ Cause of pain } \\
\hline From heart & 252 & 68.7 (63.6 to 73.4 ) & 304 & 71.2 (66.6 to 75.4 ) \\
\hline
\end{tabular}

$S D=$ standard deviation.

A range of other variables were collected and have been included in the analysis, as in previous analysis they have been shown to be important predicting factors of reported healthcare seeking. ${ }^{13}$ These include a measure of socioeconomic position (socioeconomic index), which was derived from data on car ownership, education, housing tenure, household utilities, and consumer durables. These variables were dichotomised to a score of 0 (more affluent position) or 1 (less affluent position); the scores on each of these factors were added to produce five categories (0-4); however, due to low numbers, groups 3 and 4 were aggregated. A score responders reporting th contact GP, by age group. of 0 reflects the most affluent group compared to group 3, the most deprived. Responders were also asked to rate the degree of anxiety they would experience relating to the symptoms described (dichotomised into very worried versus reasonably worried, slightly worried, and not worried at all); their self-diagnosis of the likely origin of the pain (dichotomised into pain originating from the heart compared to other sources); to select from a list of chronic illnesses (including heart conditions, diabetes, high blood pressure); and about their attitudes to doctors and to health.

\section{Data analysis}

Responses to the symptom vignette were compared across age groups, stratified by sex. Proportions reporting they would contact the GP for each age group were calculated, and differences in proportions tested using $\chi^{2}$. The impact of age on reported healthcare seeking was then explored using multivariable logistic regression. Odds ratios were calculated to compare the odds of reporting intended contact with the GP for each increasing age band compared to the reference category. Unadjusted and adjusted analyses (model including socioeconomic index, anxiety, and origins of pain) were performed, and possible interactions between sex and age were tested. All analysis was conducted on complete data using Stata (version 8).

\section{RESULTS}

Table 1 presents descriptive data on the outcome (reported willingness to consult the GP), the main explanatory variable (age group), and other measures included in the final analysis (socioeconomic index, anxiety relating to symptoms, and self-diagnosis of pain origin). Of the 794 responders included in the final analysis, 53.8\% were female and $11.2 \%$ were aged 70 years or over. The age range of responders was 30-83 years (mean 53 years, standard deviation (SD) 13 years). The majority of responders felt, having read the symptom vignette, that the pain was likely to originate from the heart $(70.0 \%)$, which did not appear to differ between the sexes, yet only $22.2 \%$ expressed they would be very anxious following the symptoms.

When the relationship between age and reported willingness to contact a GP was examined, there was a general trend that suggested increasing willingness to contact with increasing age (Figure 1). When all the data were considered together, the greatest proportion reporting contact would be made with the GP fell within the 60-69-year-old age band. However, when data were stratified by sex, this pattern remained for the male group, yet among 
Table 2. Association between age group and reported healthcare seeking by sex.

\begin{tabular}{|c|c|c|c|c|}
\hline \multirow[b]{2}{*}{ Age, years } & \multicolumn{2}{|c|}{ Males $(n=367)$} & \multicolumn{2}{|c|}{ Females $(n=427)$} \\
\hline & $\begin{array}{c}\text { OR }(95 \% \mathrm{Cl}) \\
P \text {-value }\end{array}$ & $\begin{array}{c}\text { OR }(95 \% \mathrm{Cl}) \\
P \text {-value }\end{array}$ & $\begin{array}{c}\text { OR }(95 \% \mathrm{Cl}) \\
P \text {-value }\end{array}$ & $\begin{array}{c}\text { OR }(95 \% \mathrm{Cl}) \\
P \text {-value }\end{array}$ \\
\hline$<40$ & 1.00 & 1.00 & 1.00 & 1.00 \\
\hline \multirow[t]{2}{*}{$40-49$} & 1.63 (0.88 to 3.02$)$ & 1.53 (0.77 to 3.02$)$ & 1.25 (0.67 to 2.36$)$ & 1.10 (0.55 to 2.19$)$ \\
\hline & 0.10 & 0.20 & 0.50 & 0.80 \\
\hline \multirow[t]{2}{*}{$50-59$} & $1.63(0.87$ to 3.04$)$ & 1.32 (0.66 to 2.66$)$ & 1.14 (0.66 to 1.99$)$ & 1.26 (0.69 to 2.29$)$ \\
\hline & 0.10 & 0.40 & 0.60 & 0.50 \\
\hline \multirow[t]{2}{*}{$60-69$} & 6.18 (3.06 to 12.45$)$ & 5.59 (2.64 to 11.81$)$ & 1.86 (1.02 to 3.40$)$ & 1.55 (0.80 to 3.03$)$ \\
\hline & $<0.001$ & $<0.001$ & 0.045 & 0.20 \\
\hline \multirow[t]{2}{*}{$\geq 70$} & 1.76 (0.80 to 3.87$)$ & 1.50 (0.64 to 3.55$)$ & 3.04 (1.39 to 6.68$)$ & 3.84 (1.63 to 9.04$)$ \\
\hline & 0.20 & 0.40 & 0.006 & 0.002 \\
\hline
\end{tabular}

${ }^{a}$ Unadjusted P-value. ${ }^{\mathrm{b}} \mathrm{P}$-value adjusted for socioeconomic position, anxiety about symptoms and self-diagnosis. Test for interaction with sex $\mathrm{P}=0.027$. $\mathrm{OR}=$ odds ratio.

females the greatest proportion reporting they would contact the GP was among the oldest age group (70 years and above).

Table 2 presents the findings from the logistic regression analysis. Given the possible interaction between age and sex noted in the descriptive analysis, odds ratios were only calculated for males and females separately. For men, all age bands indicated greater odds of reported healthcare seeking compared to those aged under 40 years. The greatest increase of odds was noted for the age group 60-69 years, who had over five times greater odds of reported contact with the GP in the fully adjusted model. For women, as for men, all age categories indicated higher odds of reported contact with the GP compared to the youngest age group; however, this was strongest in the oldest category. Those aged 70 years and older were just under four times more likely to report healthcare seeking compared to those under 40 years. The test for interaction provided evidence for an interaction effect between age and sex $(P=0.027)$.

Attempts were made to find possible explanations for the observations through consideration of other variables available in the dataset, for example GP consultations over the previous year, previous history of heart disease (and other chronic illness including diabetes and high blood pressure), or family history of cardiac symptoms, attitudes to doctors, and attitudes to health. However, when these variables were entered into the models they had very little impact on the findings (data not presented).

\section{DISCUSSION}

\section{Summary of main findings}

This study identified differences in the propensity to seek health care by age and sex in a general practice population, in response to a standard set of symptoms that most responders perceived to originate from the heart. In particular, men aged 60-69 years, and women aged 70 years and over were more likely to report healthcare seeking than younger responders. It is unclear why the difference did not remain for men aged over 70 years, although it was possibly due to smaller subsample sizes for males in older age groups. The findings were not explained by previous GP utilisation, experience of chronic illness, attitudes to doctors, or attitudes to health.

\section{Strengths and limitations of the study}

The study reported here is different from many of the other studies attempting to quantify illness behaviour across sociodemographic groups by linking reported consultation behaviour to a given set of symptoms. It could be argued that reported behaviour in response to artificial symptoms does not necessarily relate to real-life behaviour. However, it has been demonstrated that reported tendency to consult is predictive of observed consultation. ${ }^{19,20}$

The value of using the symptom vignette is the attempt to standardise symptomatology across all responders. Nevertheless, it is important to note that presenting just one symptom scenario does not account for the various ways in which different sociodemographic groups are likely to experience chest pain in real life. For example, it has been shown that older people and women do have less 'typical' symptom experiences associated with acute myocardial infarction. ${ }^{21,22}$ This needs to be taken into account when interpreting the results.

In the study sample, responders were slightly older than non-responders and were more likely to be female. This would imply that the study gave conservative estimates of the associations of 
reported consultation with age and sex. Although the study was based on a single general practice population, this practice was selected to represent a wide range of social strata.

\section{Comparison with existing literature}

As noted above, there is evidence to suggest a reluctance among older people to seek treatment, ${ }^{14}$ which may be due to 'age-attribution'. ${ }^{17} \mathrm{~A}$ health diary study among older people in rural areas also reported that most symptoms were ignored or managed by responders themselves (that is, selfmedication), and when others are consulted these are most likely to be friends and relatives rather than health professionals. ${ }^{23}$ The present findings, however, did not support this view. The increase in hypothetical consultation behaviour with older age that was found, is more consistent with the observed higher GP consultation rates among older people, using data from national surveys. ${ }^{24}$

In fact, it has been noted that non-consulting older people are a low-risk group in relatively good health, ${ }^{25,26}$ and that any unidentified needs of older people may be those that are 'simple and remedial rather than serious or complex'. ${ }^{27}$ Refusal of preventative interventions among older people, for example influenza immunisation, appears to be bound to some older people feeling healthy, and therefore not 'at risk' or in need of services targeted at 'older people'. ${ }^{28}$ It is also possible that unmet need is symptom or condition specific, for example it has been observed that rates of consultation for mental health problems are low among older people, especially men. ${ }^{29}$ However, there is little other research investigating symptoms of potential heart symptomatology and illness behaviour.

The results suggest that the inequity that has been demonstrated in access to cardiology services by age is not likely to be due to the patient's illness behaviour, as, overall, older people are more likely than younger people to consult their doctors, especially women aged 70 years and over. Bond and colleagues previously examined the independent effects of both age and sex on the treatment of cardiac hospital patients in two district general hospitals. They reported that patients aged over 75 years, and women, independently, were significantly less likely to receive indicated interventions in one hospital; ${ }^{1}$ and although significant age effects were found in the second hospital, there were fewer independent sex effects..$^{30}$ While the latter were all patients who had actually been referred (or admitted via emergency services) to specialist services, the reasons for the inequity experienced post-referral were unknown. The study reported here suggests that inequity is not necessarily linked to patient behaviour, or to patients dismissing their symptoms as a consequence of age.

There is little evidence to suggest whether older people and women refuse investigations that they have been offered, but there was little indication of this in the study of Bond and colleagues. ${ }^{30}$ One study in the US has observed that women did not differ from men in their preference for receipt of cardiac catheterisation; however, those of lower educational background were more likely to disagree with a physician's recommendation for this procedure (yet this did not account for all of the educational difference observed). ${ }^{31}$

\section{Implications for future research and clinical practice}

The collective evidence of such research and the study reported here suggests that clinician behaviour may be responsible for the documented inequities in cardiac treatment once patients have consulted over symptoms of angina. One alternative explanation would be that the symptom scenario presented in the vignette does not reflect the way in which serious chest pain symptoms are experienced by women and older people. ${ }^{21,22}$ Therefore, discrepancies seen in the provision of secondary and tertiary care for these groups may be due to those individuals being less likely to recognise 'atypical' cardiac symptoms, ${ }^{32}$ and, hence, not seeking help. Another alternative explanation might be the different ways older people and women present themselves during consultations, which then leads to different treatment protocols. There is some evidence of different illness concepts between doctors and patients, which influence the consultation. ${ }^{33}$ It is also possible that, even once patients have presented with their symptoms, the comorbidity that is often present in older people may make identification of the health problem more difficult for the doctor, ${ }^{34}$ leading to treatment differences.

\section{Funding body}

The research was funded by the UK South \& West NHS Research and Development Directorate

(C/MV/10/04.97/Donovan)

\section{Ethical approval}

The study had full approval from the local research ethics committee (LREC Project 45/97)

\section{Competing interests}

The authors have stated that there are none

Acknowledgements

The research was funded by the UK South and West NHS Research and Development Directorate. The authors would like to express our gratitude to the responders who took the time to complete the postal questionnaire.

Discuss this article

Contribute and read comments about this article on the Discussion Forum: http://www.rcgp.org.uk/bjgp-discuss 


\section{REFERENCES}

1. Bowling A, Bond M, McKee D, et al. Equity in access to exercise tolerance testing, coronary angiography, and coronary artery bypass grafting by age, sex and clinical indications. Heart 2001; 85(6): 680-686.

2. Bowling A. Honour your father and mother: ageism in medicine. Br J Gen Pract 2007; 57(538): 347-348.

3. Morris RW, Whincup PH, Papacosta O, et al. Inequalities in coronary revascularisation during the 1990s: evidence from the British regional heart study. Heart 2005; 91(5): 635-640.

4. Department of Health. National service framework for older people London: Department of Health, 2001

5. Ramsay SE, Morris RW, Papacosta O, et al. Secondary prevention of coronary heart disease in older British men: extent of inequalities before and after implementation of the National Service Framework. J Public Health 2005; 27(4): 338-343.

6. Lopez AD, Murray CCJL. The global burden of disease, 1990-2020. Nat Med 1998; 4(11): 1241-1243.

7. Department of Health. National service framework for coronary heart disease. London: Department of Health, 2000.

8. Shaw M, Maxwell R, Rees K, et al. Gender and age inequity in the provision of coronary revascularisation in England in the 1990s: is it getting better? Soc Sci Med 2004; 59(12): 2499-2507.

9. Goddard M, Smith P. Equity of access to health care services: theory and evidence from the UK. Soc Sci Med 2001; 53(9): 1149-1162.

10. DeWilde S, Carey I, Bremner S, et al. Evolution of statin prescribing 1994-2001: a case of agism but not of sexism? Heart 2003; 89(4): 417-421.

11. Bowling A. Ageism in cardiology. BMJ 1999; 319(7221): 1353-1355.

12. The TIME I. Trial of invasive versus medical therapy in elderly patients with chronic symptomatic coronary-artery disease (TIME): a randomised trial. Lancet 2001; 358(9286): 951-957.

13. Adamson J, Ben-Shlomo Y, Chaturvedi N, Donovan J. Ethnicity, socio-economic position and gender - do they affect reported health-care seeking behaviour? Soc Sci Med 2003; 57(5): 895-904.

14. Williamson J, Stokoe IH, Gray S, et al. Old people at home. Their unreported needs. Lancet 1964; 1: 1117-1120.

15. Sanders C, Donovan JL, Dieppe PA. Unmet need for joint replacement: a qualitative investigation of barriers to treatment among individuals with severe pain and disability of the hip and knee. Rheumatology 2004; 43(3): 353-357.

16. Sanders C, Donovan J, Dieppe P. The significance and consequences of having painful and disabled joint in older age: co-existing accounts of normal and disrupted biographies. Sociol Health Illn 2002; 24: 227-253.

17. Walters K, Iliffe S, Orrell M. An exploration of help-seeking behaviour in older people with unmet needs. Fam Pract 2001; 18(3): 277-282.

18. Emslie C, Hunt K, Watt G. Invisible women? The importance of gender in lay beliefs about heart problems. Sociol Health Illn 2002; 23: 203-233.

19. Van der Meer JBW, Mackenbach JP. Low education high GP consultation rates: the effect of psychosocial factors. J Psychosom Res 1997; 44(5): 587-597.

20. Reijneveld S, Stronks K. The validity of self-report use of health care across socioeconomic strata: a comparison of survey and registration data. Int J Epidemiol 2001; 30(6): 1407-1414.

21. Isaksson RM, Holmgren L, Lundblad D, et al. Time trends in symptoms and prehospital delay time in women vs. men with myocardial infarction over a 15 -year period. The Northern Sweden MONICA Study. Eur I Cardiovasc Nurs 2007. doi: 10.1016/j.ejcnurse.2007.09.001

22. Meischke H, Larsen MP, Eisenberg MS. Gender differences in reported symptoms for acute myocardial infarction: Impact on prehospital delay time interval. Am J Emerg Med 1998; 16(4): 363-366.

23. Stoller EP, Forster LE. Patterns of illness behavior among rural elderly: preliminary results of a health diary study. J Rural Health 1992; 8(1): 13-26.

24. Walker A, Walker A, Coulhard M, et al. Living in Britain. Results from the 2000 General Household Survey, 2001. London: The Stationery Office, 2001.

25. Williams E, Barley N. Old people not known to the genera practitioner: low risk group. $B M J 1985 ; 291: 251-254$.

26. Ebrahim S, Hedley R, Sheldon M. Low levels of ill health among elderly non-consulters in general practice. BMJ 1984; 289: 1273-1276.

27. Dixon-Woods M, Kirk D, Agarwal S, et al. Vulnerable groups and access to health care: a critical interpretive review. Report for the National Co-ordinating Centre for NHS Service Delivery and Organsation R\&D (NCCSDO). London: NCCSDO, 2005.

28. Evans MR, Prout H, Prior L, et al. A qualitative study of lay beliefs about influenza immunisation in older people. Br J Gen Pract 2007; 57(538): 352-358.

29. Shah R, McNiece R, Majeed A. General practice consultation rates for psychiatric disorders in patients aged 65 and over: prospective cohort study. Int J Geriatr Psychiatry 2001; 16(1): 57-63.

30. Bond $\mathrm{M}$, Bowling $\mathrm{A}, \mathrm{McKee} \mathrm{D}$, Kennelly $\mathrm{M}$, et al. Is age a predictor of access to cardiac services? J Health Serv Res Policy 2003; 8(1): 40-47.

31. Schecter A, Goldschmidt-Clermont P, McKee G, et al. Influence of gender, race and education on patient preferences and receipt of cardiac catheterizations among coronary care unit patients. Am J Cardiol 1996; 78(9): 996-1001.

32. Leslie WS, Urie A, Hooper J, Morrison CE. Delay in calling for help during myocardial infarction: reasons for the delay and subsequent pattern of accessing care. Heart 2000; 84(2): 137-141.

33. Scheuer E, Steurer J, Buddeberg C. Predictors of differences in symptom perception of older patients and their doctors. Fam Pract 2002; 19(4): 357-361.

34. Meyer T, Klemme H, Herrmann C. Depression but not anxiety is a significant predictor of physicians' assessments of medical status in physically ill patients. Psychother Psychosom 2000; 69(3): $147-154$. 